\title{
Utilizing Technology to Support the Development of Empathy
}

\author{
Shaundra Bryant Daily \\ Massachusetts Institute of \\ Technology, Media Lab \\ 77 Massachusetts Ave E15-447 \\ Cambridge, MA 02139

\section{Karen Brennan} \\ Massachusetts Institute of \\ Technology, Media Lab \\ 77 Massachusetts Ave E15-120h \\ Cambridge, MA 02139
}

\begin{abstract}
Empathy is a fundamental component of positive and productive human relationships. In the context of civic engagement, the ability to "stand in the shoes of another" increases opportunities to avoid

miscommunication and misunderstandings, to work together in cooperative settings, and, as a result create innovative solutions to social issues. In this proposal, we present a fourteen-week workshop being conducted with a diverse group of middle school children to use technology to foster the development of empathy and support civic engagement.
\end{abstract}

\section{Keywords}

Empathy development, civic engagement, intergroup relations, storytelling

\section{ACM Classification Keywords}

K.3.2 [COMPUTERS AND EDUCATION]: Computer and Information Science Education - Curriculum; K.4.m [COMPUTERS AND SOCIETY]:Miscellaneous

\section{Introduction}

The purpose of this research is to design and implement a technology-based curriculum geared toward helping youth develop their empathic capacities. We first present the connection between empathy and civic engagement. Then, we describe a 
collaborative study we are currently carrying out with a journalist.

Research has found consistent ties between empathy and civic engagement [6]. Civic engagement "includes the ability to participate in civic actions such as community service and initiatives to further improve the public sphere, to engage in 'civic conversations', and to develop publicly deliberated civic knowledge, attitudes, and decisions" [2]. It is imperative, then, that certain conditions exist in order to create an environment that is conducive to civic engagement.

Community members must understand, care about, and be driven to communicate injustices, and hopefully take action towards changing them [3]. Once community members decide to effectuate change, additional issues they may encounter are the challenges associated with working within diverse groups [1]. Understanding injustices and cooperating with others both hinge on one's ability to empathize.

\section{Related Work}

The role of technology in generating understanding and/or fostering civic engagement has included video case studies, information and communication technology mediated cultural exchange, and explorations in virtual environments $[4,7,8,12]$. Bers [2] work with Zora, a 3-D virtual environment, provides evidence of the feasibility for technology to engage youth in exchanging dialogue and communicating individual ideas, opinions, and information about civic life.

\section{Research Approach}

We have the dual goal of examining the development of empathy and designing an effective curriculum for Scratch, a programming environment designed to cultivate the technological, social, and expressive capacities of young people [10], as a form of civic media. Civic media, here, is defined as "any form of communication that strengthens social bonds within a community or creates a strong sense of civic engagement." [9] Therefore, our approach is that of design-based research which uses natural laboratories to both study and develop effective learning environments [11].

Our context is a 14-week apprenticeship with Citizen Schools, a network of programs that connects students to adult volunteers in after-school settings [5]. Although extensively describing the curricular plan for this apprenticeship is beyond the scope of this brief proposal, here, I provide an overview of our context and curriculum framework.

\section{Design-Based Sessions}

Each session begins with an opening activity that is designed to have the participants: (1) revisiting the previous weeks' themes and experiences, (2) engaging in acts of community (and predominantly physical) construction, and (3) setting the tone and expectations for the day's lesson by exploring a theme. Next, we work through a series of activities that elaborate on the session's theme. Each session includes three central activities that build capacities in the areas of journalism (e.g., listening actively, asking questions, understanding representations), emotion (e.g., individual identity, group interaction, shared understanding), and technology (e.g., programming, sensing, remixing). 
This capacity building is demonstrated in student design-driven projects constructed with Scratch. Each session concludes with reflections on the day's activities, which includes opportunities for the students to articulate their learning through teaching-back experiences.

\section{Trajectories of Awareness}

We have numerous learning objectives related to the themes of journalism, emotion, and technology that we have structured across the cognitive, affective, and sensorimotor domains. Participants begin the apprenticeship with experiences that encourage them to explore trajectories of individual, and then community, identity. Simultaneously, participants explore trajectories of understanding their own, and then others', emotions. These two paths, shown in figure 1 , are what we call "trajectories of awareness".

Throughout these concurrent processes, students will be utilizing a variety of tools (digital cameras, audio recorders) and techniques (interviewing, mapping) to document their community spaces and to create rich, interactive, multi-threaded narratives.

These multi-threaded narratives will be used to move students beyond their personal perspectives and challenge them to see the world through the eyes of another. The curriculum is designed to guide students through trajectories of awareness and enable their capacity for perspective taking.

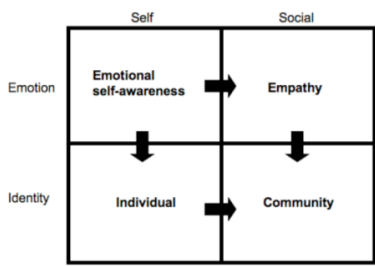

figure 1. Trajectories of Awareness

\section{Questions and Methodology}

Again, the structure of this curriculum is to support the development of empathy in the youth we are working with. Specific research questions we are investigating include:

1. Can the creation of multi-threaded narratives support perspective taking abilities?

2. Can Scratch be used as a form of civic media?

3. Will this technology-based curriculum enable students to talk about and understand their own emotions and the emotions of others? (figure 1)

4. Will this technology-based curriculum support students' understandings of their identity as individuals as well as a part of their community? (figure 1)

Participants. Six male and four female middle school students ranging in age from 11 to 13 are participants in this apprenticeship. Students all come from a middle school in Boston, Massachusetts; however, because of busing programs, their residences are dispersed throughout the city. Because of this mix of students, there are strong histories of racial and ethnic tension within the school, making themes of understanding and working together particularly appropriate. 
Data Collection and Analysis. We will utilize a variety of data sources to address the research questions. All students fill out weekly questionnaires that invite feedback on their experiences and understandings of the apprenticeship, and their desires for future experiences. At the end of the apprenticeship, members of the research team will conduct individual semi-structured interviews. Field notes and analysis of artifacts created within the workshop will also be used to develop comprehensive themes of the workshop experiences.

\section{Conclusions}

In this proposal, we describe a novel approach to teaching perspective taking that is embedded in a curriculum for the Scratch programming environment, designed to support the development of empathy, and therefore, civic engagement. The goals of this research mesh well with the IDC themes of design for civic involvement and emotional well being of children. We have just finished our eighth week of the apprenticeship; however, at the time of this conference, we will have finished all fourteen weeks. At the consortium, we will present our findings along with our plans for the next iteration of the apprenticeship with the hopes of receiving feedback that will help shape our direction.

\section{Acknowledgements}

We would like to thank Colleen Kaman for countless hours spent conceptualizing and implementing this project.

\section{References}

[1] Aronson, E. Nobody left to hate. Henry Holt, New York, NY, USA, 2001.
[2] Bers, M., \& Chau, C. Fostering civic engagement by building a virtual city, Journal of Computer-Mediated Communication. 11,3 (2006).

[3] Batson, C.D, Chang, J., Orr, R., Rowland, J. Empathy, Attitudes, and Action: Can Feeling for a Member of a Stigmatized Group Motivate One to Help the Group? Personality and Social Psychology Bulletin. 28, 12 (2002), 1656-1666.

[4] Cassell, J. "We Have these Rules Inside": The Effects of Exercising Voice in a Children's Online Forum. In Children in the Digital Age. S. Calvert, R. Cocking and A. Jordan (Eds). Praeger Press, New York, 2002, 123-144.

[5] Cavanagh, S. Citizen schools: an after-hours adventure--professionals mentoring middle-grades students, Education Week, 26,19 (2002), 1-2.

[6] Encouraging civic engagement: how teens are (or are not) becoming responsible citizens,

http://www.childtrends.org/files/K6Brief.pdf. accessed January 15, 2008.

[7] Lee, J. J., \& Hoadley, C. M. Ugly in a world where you can choose to be beautiful: teaching and learning about diversity via virtual worlds In , Pro ICLS 2006, 383-389.

[8] Lin, X., \& Kinzer, C. K. The importance of technology for making cultural values visible, Theory into Practice, 42,3, 2003, 234-42.

[9] MIT Center for Future Civic Media. http://civic. mit.edu/?page_id=36.

[10] Maloney, J., Burd, L., Kafai, Y., Rusk, N., Silverman, B., \& Resnick, M. Scratch: a sneak preview [education], Proc. CCCC 2004, 104-109.

[11] Sandoval, W. A., \& Bell, P. Design-based research methods for studying learning in context: introduction, Educational Psychologist, 39,4, (2004) 199-201.

[12] Warner, R. E. Enhancing teacher affective sensitivity by a videotape program. Journal of Educational Research, $77,6(1984), 366-68$ 